\title{
Art in Science
}

\section{Art in Science: Giovanni Paolo Mascagni and the Art of Anatomy}

\author{
Berardo Di Matteo MD, Vittorio Tarabella MA, \\ Giuseppe Filardo MD, Anna Viganò MA, \\ Patrizia Tomba MA, Elizaveta Kon MD, \\ Maurilio Marcacci MD
}

N ote from the Column Editors: Artists have studied anatomy for centuries, if not longer, to better understand the human form. For similar timeframes, anatomical dissections have been carried out by those curious about what lies beneath the skin in an effort to explain injury and illness, as well as to discover treatments for various conditions. Frequently, the artist and the physician-scientist have partnered to leverage ones skills in order to assist the other in achieving their goal(s). At times, as was the case

Note from the Editor-in-Chief:

I am pleased to introduce the next installment of our "Art in Science" column coedited by Gary and Linda Friedlaender. Linda

Friedlaender is the Curator of Education at the Yale Center for British Art; Gary is the Chair of the Department of Orthopaedics and Rehabilitation at Yale School of Medicine. In this latest installment, Berardo Di Matteo MD and colleagues from the Rizzoli Orthopaedic Institute in Bologna, Italy share their observations of the Italian anatomist Giovanni Paolo Mascagni from a fascinating vantage point: The interface of art and medicine.

The authors (BDM, VT, GF, EK, MM, AV, PT) are employees of Rizzoli Orthopaedic Institute, Bologna, Italy.

The institution of one or more of the authors (BDM, VT, GF, EK, MM, AV, PT) has received, during the study period, funding from Italian State through " 5 per mille (year 2010)" project. with Giovanni Paolo Mascagni (1755-1815), the artist and the physician-scientist were one in the same. Mascagni, however, depended on skilled engravers to reproduce his observations for publication. This was the required technology for mass reproductions at the time. The remarkable illustrations of Frank H. Netter MD (1906-1991) had the advantage of more faithful means to replicate his art for our contemporary print media [8].

What both of these physicianartists, and their successful counter-

All ICMJE Conflict of Interest Forms for authors and Clinical Orthopaedics and Related Research ${ }^{\mathbb{R}}$ editors and board members are on file with the publication and can be viewed on request.

The opinions expressed are those of the writers, and do not reflect the opinion or policy of $C_{O R R^{\circledR}}$ or the Association of Bone and Joint Surgeons ${ }^{\circledR}$.

B. Di Matteo MD (ه), V. Tarabella MA, G. Filardo MD, E. Kon MD,

M. Marcacci MD

Biomechanics Laboratory, Rizzoli

Orthopaedic Institute, Bologna, Italy

e-mail: berardo.dimatteo@gmail.com

A. Viganò MA, P. Tomba MA

Donazione Putti, The Scientific Libraries

of Rizzoli Orthopaedic Institute,

Bologna, Italy parts throughout the history of medicine, had in common were their ability to carefully observe, interpret, and convey their insights through the visual arts.

We are indebted to our colleagues at the Rizzoli Orthopaedic Institute in Bologna, Italy for sharing another special work from this remarkable library.

Gary E. Friedlaender MD, Linda K. Friedlaender BA, MS

\section{Anatomy: A Question of Art and Science}

For centuries, the human body was considered an inviolable treasure chest, as religious authorities largely restricted anatomical dissections. The first scientists to attempt these kinds of studies often were forced to perform their research in secret, far from the eyes of the clergy. It was only at the beginning of the 13th century that we find the first traces of public anatomical dissection performed by Mondino de' Liuzzi, professor of anatomy at the University of Bologna [2]. From that moment on, radical new ideas (both religious and scientific) were proposed. Dissections became a common method 


\section{Art in Science}

to teach human anatomy throughout Europe.

Anatomy is widely regarded as the discipline that bridges art and science [8] - a field where the ingenuity of the scientist and the creative power of the artist can combine to contribute to a more-complete understanding of human complexity.
Enter Giovanni Paolo Mascagni (1755-1815, Fig. 1), an enlightened Italian anatomist who was among the first to understand the power of blending art and science in this way. Mascagni spent the early years of the 19th century as a teacher - both of physicians and artists. His most expansive and ambitious artistic endeavour, Icones Anatomiae Universae (Complete Anatomy Tables) [6], is widely renowned for its significant observations and grandiose layout (102 cm length, $75 \mathrm{~cm}$ width). Mascagni's Atlas is one of the largest anatomy atlases ever realized, with the precise aim of reproducing the human body at a 1:1 ratio (Fig. 2).

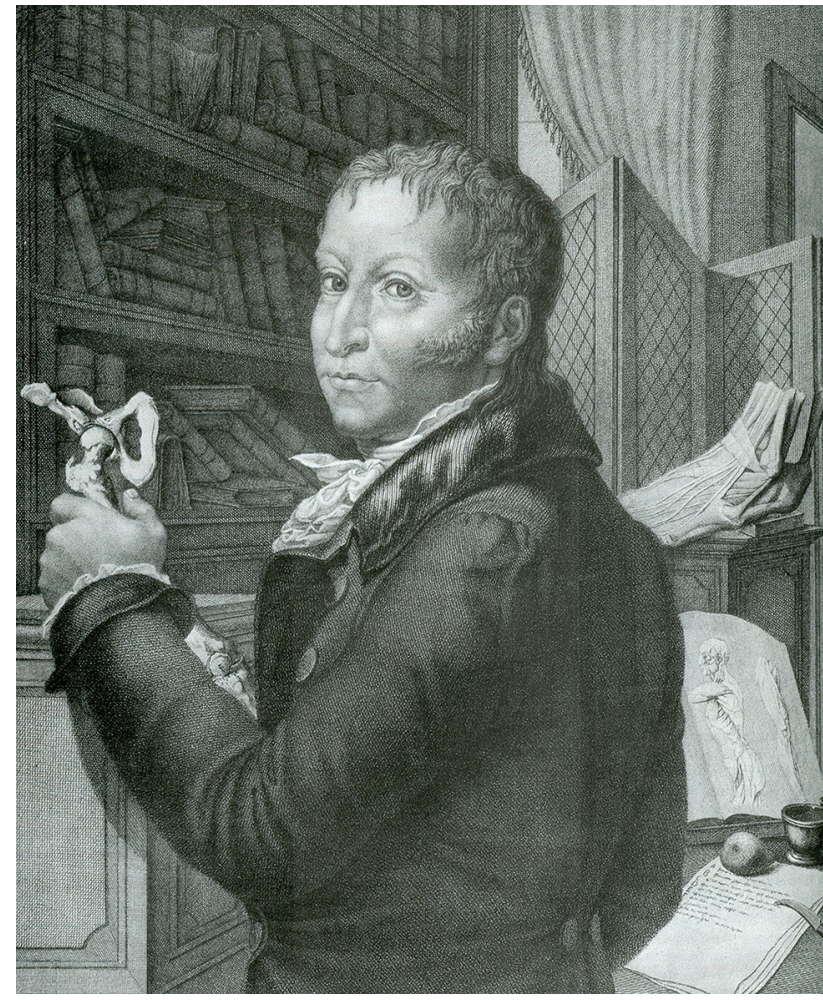

Fig. 1 Portrait of Giovanni Paolo Mascagni in his office. Copper engraving by Roberto Focosi (drawing) and Luigi Rados (engraving), 19th Century. On the right, it is possible to see the anatomical model of a foot, an anatomy book, and Mascagni's notes. Republished with permission from The Library of the Rizzoli Orthopaedic Institute.

\section{Making a Name for Himself}

After graduating from the University of Siena in 1777, Pietro Tabarrani, a renowned anatomist of the time, noticed Mascagni and wanted him to be his assistant. Tabarrani died in 1780 and the Grand Duke Leopold I of Tuscany, who would later become Leopold II, Holy Roman Emperor, appointed Mascagni as the new anatomy lecturer at the University of Siena, his alma mater. These are the years of Mascagni's greatest medical achievement - his revolutionary investigation into the lymphatic system. In 1784, the Academy of Sciences of Paris launched a competition for the best work demonstrating the lymphatic vessels [3]. The scientific committee awarded a special prize for Mascagni's research, and his work was immediately published in Italian, French, and German. Vasorum Lymphaticorum Corporis Humani Historia et Iconographia (Iconography and History of 


\section{Art in Science}

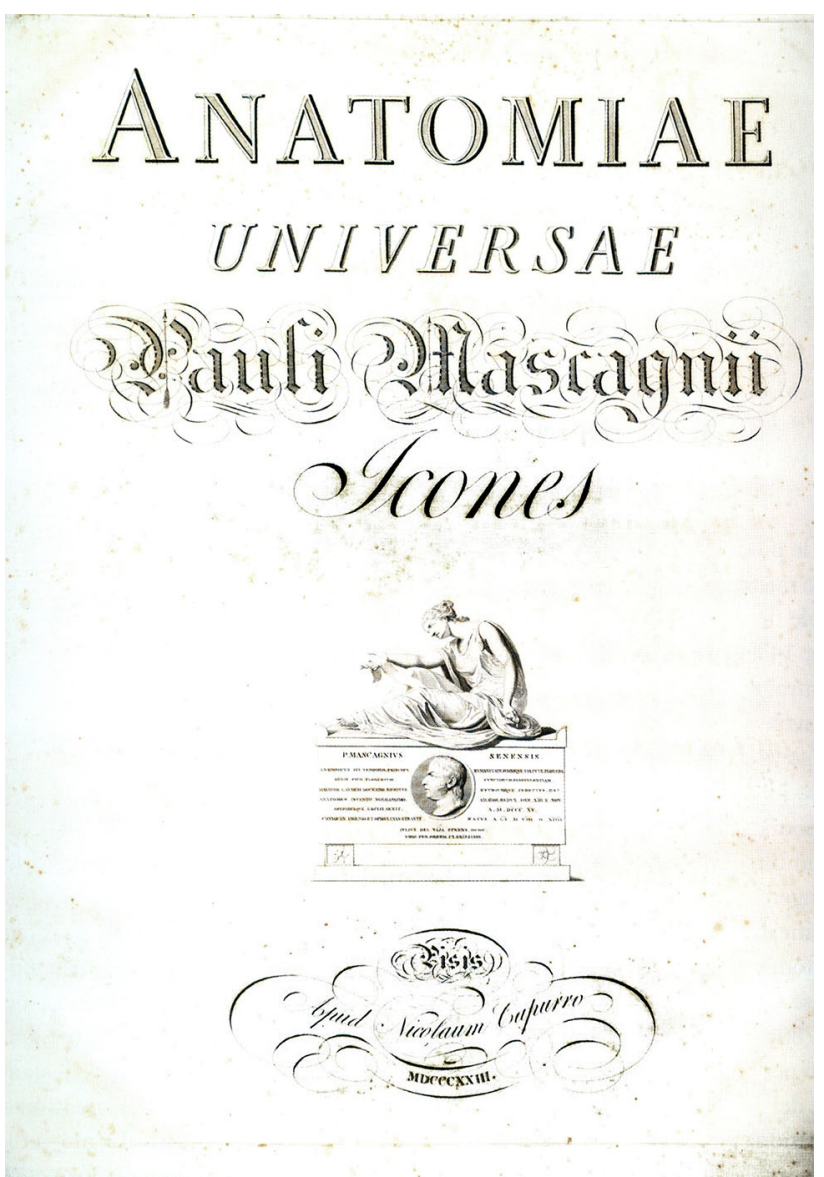

Fig. 2 The title page of the Icones Anatomia Universae. A memorial monument is depicted in the center of the page. The size of the Atlas' tables are impressive: $102 \mathrm{~cm}$ length, $75 \mathrm{~cm}$ width, which allowed for the representation of the human body in a 1:1 ratio. Republished with permission from The Library of the Rizzoli Orthopaedic Institute.

the Lymphatic Vessels of the Human Body) consists of 41 in-folio copper engravings, which according to Mascagni, "show their course in every part of the human body; accounts are given of many experiments and observations on the extremity of the blood vessels, the function of the lymphatics and the separation and elaboration of the various humours which serve as nourishment for tissues, and other use." [7]. Mascagni's research was the first systematic description of the lymphatic system. He was credited with discovering approximately 50\% of the entire lymphatic vessels of the human body by using mercury as a contrast medium, with fascinating illustrations realized by Ciro Santi, a famous engraver from Bologna, Italy. His plates show an accurate and truly masterful representation of the lymphatics [4].

\section{Teacher to Physicians and Artists}

In 1807, Mascagni was placed in charge of anatomy teaching at the Academy of Fine Arts in Florence, Italy. He wrote Treatise of Anatomy [5] for his students, containing 15 large, colorful copper plates explaining the human body. This "book" was not meant to train surgeons or physicians, but artists specializing in the representation of every part of the human body - future assistants for anatomists from all around Europe. The first two plates show front and back a skeleton with ligaments; plates three to five show the front, back and sides of a muscle-man; plates six to fifteen are dedicated to specific parts of the body, depicting their actual-sizes. Antonio Serantoni, a celebrated engraver did all of the engravings. The plates are 


\section{Art in Science}

colored in a mixed way, using red crayon for the muscles and brush for the remaining structures.

\section{Untimely Death}

Focused on improving and refining the teaching of human anatomy, Mascagni started to work on a new project, a colossal Atlas of the human body made entirely by colored, actual-size plates. That was the beginning of a production that engaged Mascagni until the end of his life, which occurred unexpectedly in 1815 , due to the complications of a "putrid fever" (ie septicaemia) [1]. His heirs published his work posthumously in 1832 [6].

Mascagni's idea was to depict an average $175 \mathrm{~cm}$-tall ( 5 feet 7 inches) adult male "facie adversa et facie aversa" (front and back side; [Fig. 3]) and layer by layer, starting from the "stratum primum" (superficial muscles), and going progressively deeper to the "stratum secundum" (intermediate), the "stratum tertium" (deep muscular level), and finally down to the skeleton (Fig. 4). The engravings were made by his assistant, Serantoni, and they were almost ready for publication before Mascagni's death - at that point needing only minor adjustments. It is believed Mascagni delayed publishing the Atlas because he was waiting for the technology to print all of the tables in full color [1].

Unfortunately, after his death in 1815 , squabbles among his heirs complicated publication of this important work [3]. His heirs issued two editions of a so-called "prodrome" to Anatomia Universa - the first consisting of 20 plates and the second of 48. Neither of these selections reproduced the plates as conceived by the Mascagni, nor were

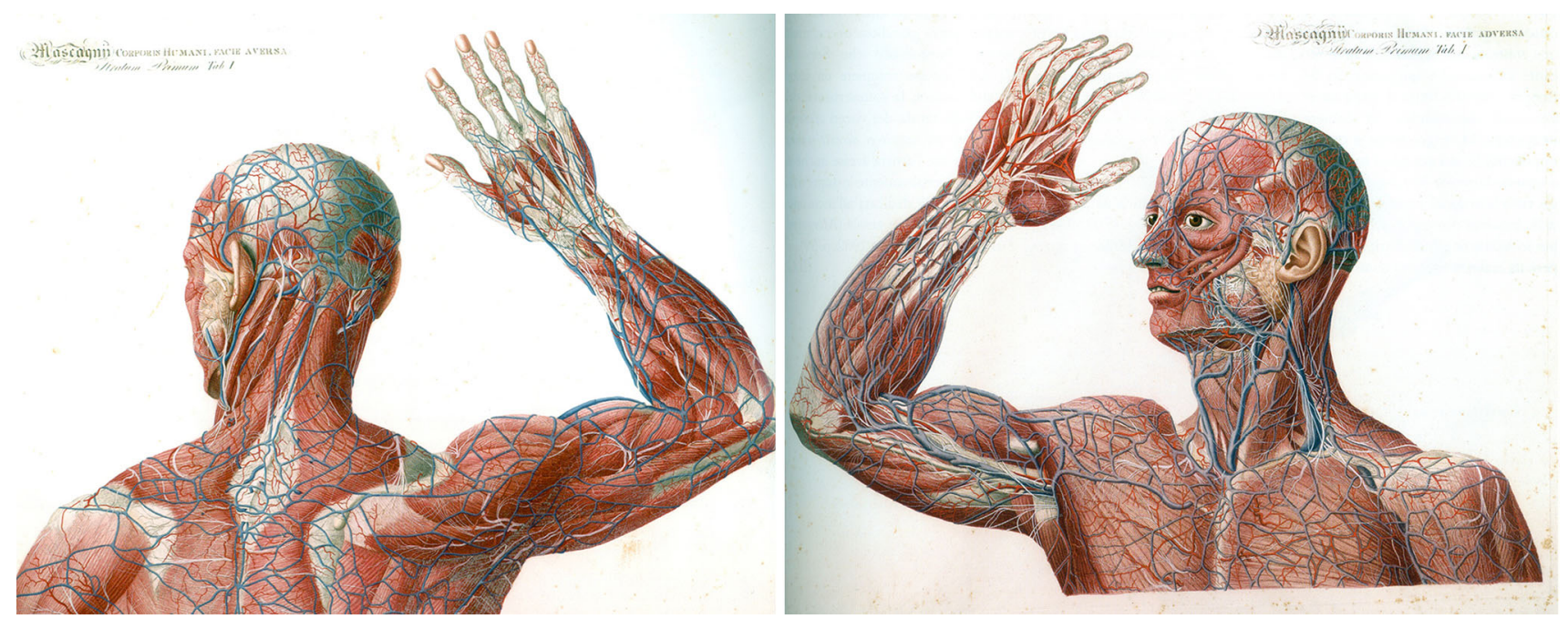

Fig. 3 A sample collage shows the front-back approach in Icones Anatomiae Universae. Muscle-layer of the upper body, front, and back view. The muscles are drawn on a flesh colored background made by crayon. The remaining parts of the body are brush colored. Republished with permission from The Library of the Rizzoli Orthopaedic Institute. 


\section{Art in Science}

they made according to the original structural concept. At the end of 1819 , Mascagni's heirs started a bitter quarrel for the copyrights of the plates.
The final edition of the work was published in nine fascicles through 9 years, one per year, from 1823 to $1832 ; 88$ plates in total were released, including the original 44 hand-colored ones conceived by Mascagni and their black and white twin duplicates, with only the outlines of the figures and
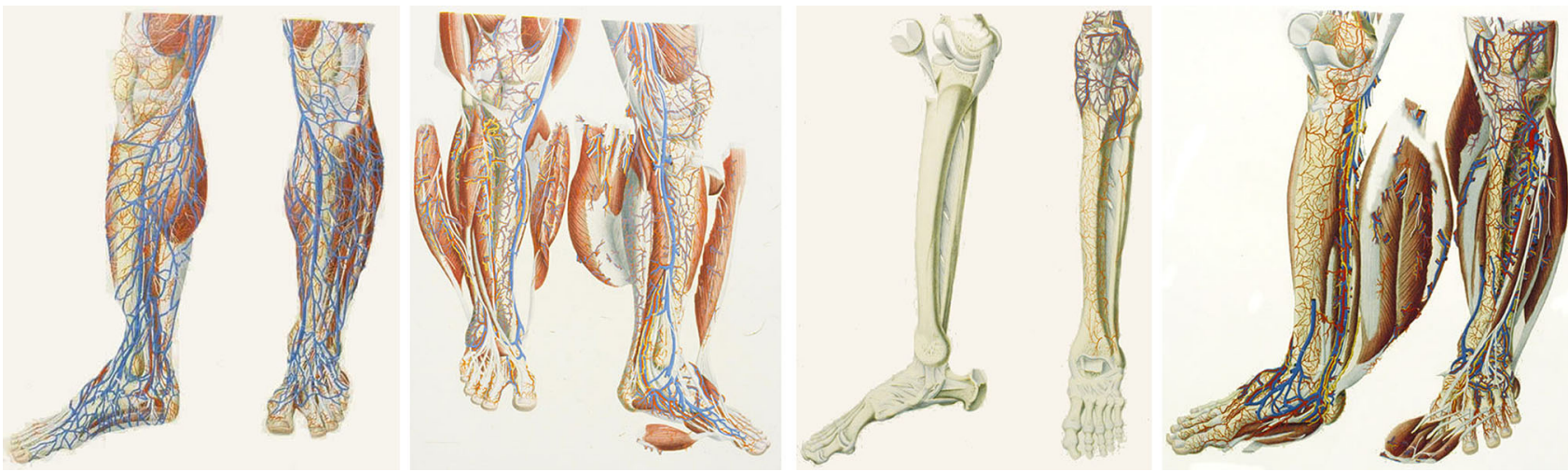

Fig. 4 A sample collage shows the layers of approach in Icones Anatomiae Universae. Lower body from the skeleton layer through the first, second, and third muscle-layer. Republished with permission from The Library of the Rizzoli Orthopaedic Institute.

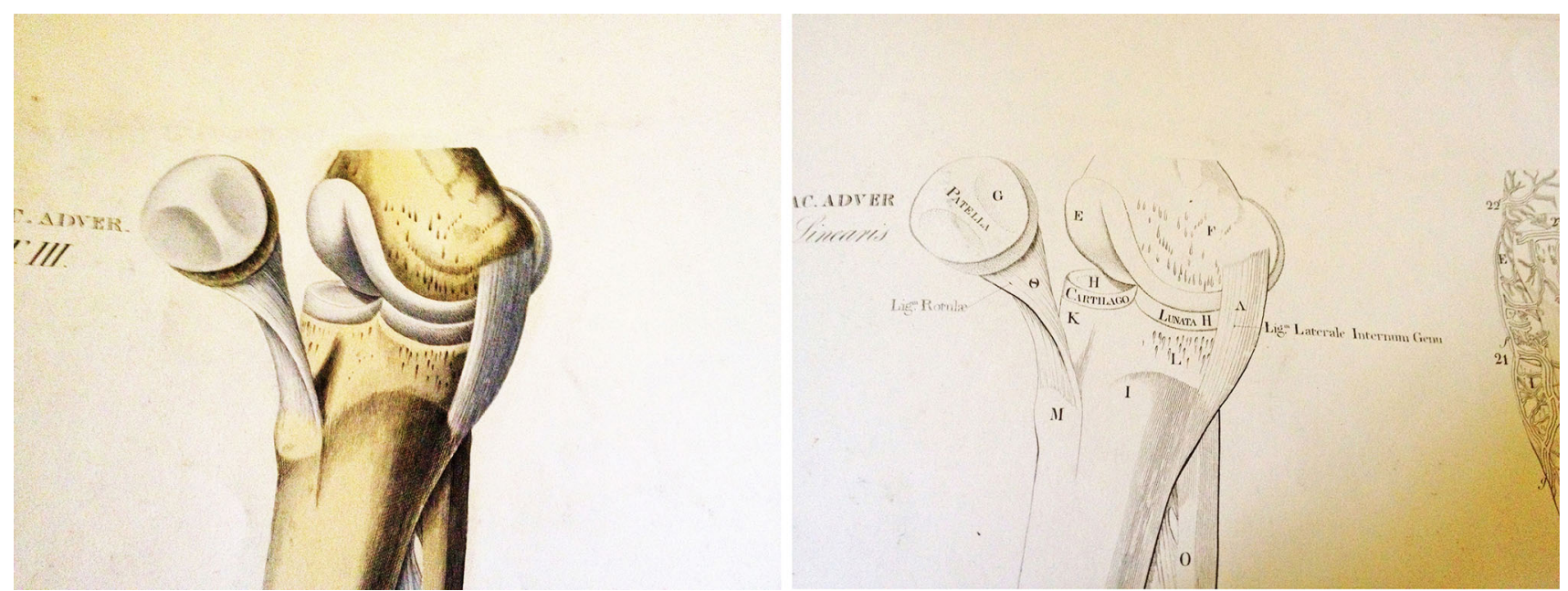

Fig. 5 A sample collage of the meniscus shows the relationship between the fully colored plates and the outline-only black and white plates. Republished with permission from The Library of the Rizzoli Orthopaedic Institute. 


\section{Art in Science}

their legends to identify the body parts (Fig. 5). The plates are so large that an entire human body can be obtained just by juxtaposing three of them, one for feet and legs, one for the lower body, and the last for the upper body and head. It contains the entire human body, (with the only exception of skin and microscopic layers) accurately represented and colored according to the standards of anatomic subjects.

\section{"To devote all his attention to Science..."}

In his unpublished autobiography, Mascagni, speaking of himself in the third person as customary for that time, wrote "to devote all his attention to this Science and, believing that his principal obligation was to teach the young and to enable them to acquire perfect knowledge of the human body, he pursued this purpose with great zeal, without neglecting the other obligation which he considered part of his professional duty, the advancement of Anatomical Science." [1]. It is clear that Giovanni Paolo Mascagni's contributions to science were matched by his groundbreaking work as an artist. As an educated man from a country with a longstanding artistic tradition, his academic activities indeed straddled the arts and the sciences, and was a genuine heir to two traditions: that of the classical anatomists and the great Renaissance artists. His Treatise of Anatomy stands as an everlasting testament to both of those traditions. This work is by any definition a masterpiece; even some 200 years after its completion, it reminds us that art and science share a common purpose - to investigate the inner nature of mankind.

Acknowledgments The authors would like to thank Liliana Draghetti (Donazione Putti, Biblioteche Scientifiche, Rizzoli Orthopaedic Institute), Keith Smith (Task Force, Rizzoli Orthopaedic Institute), Davide Puppini, and Linda Accorsi for their help.All the images reproduced in the present paper are the property of "Donazione Putti, Biblioteche Scientifiche" (Rizzoli Orthopaedic Institute, Bologna, Italy) which kindly gave their consent for the use of the images in the present manuscript.

\section{References}

1. Bertelli R. Paolo Mascagni (17551815). J Cardiovasc Surg (Torino). 1961;2:414-421.

2. Crivellato E, Ribatti D. Mondino de' Liuzzi and his Anathomia: A milestone in the development of modern anatomy. Clin Anat. 2006;19: 581-7.

3. Eimas R. The great anatomy of Paolo Mascagni. Available at: http:// www.lib.uiowa.edu/scua/bai/eimas.htm. Accessed May 12, 2014.

4. Frank M. History and Bibliography of Anatomic Illustration by Ludwig Choulant. Chicago, IL: University of Chicago Press;1920:315-320.

5. Mascagni P. [Anatomy for Scholars of Culture and Painting] [in Italian]. Firenze, Italy: Tipografia Giovanni Merenigh; 1816.

6. Mascagni P. [Complete Anatomy Table] [in Italian]. Pisa, Italy: Nicol. Capurro; 1823-1832.

7. Mascagni P. [Iconography and History of the Lymphatic Vessels of the Human Body] [in Italian]. Siena, Italy: Pazzini Carli; 1787.

8. Netter FM, Friedlaender GE. Frank H. Netter MD and a brief history of medical illustration. Clin Orthop Relat Res. 2014;472:812-819. 